
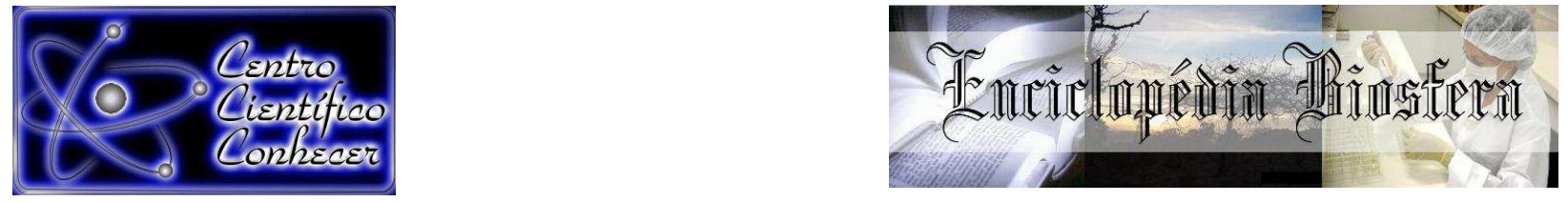

\title{
PRODUÇÃO DE MUDAS DE BRACATINGA EM DIFERENTES SUBSTRATOS
}

Alexandre de Araúijo Ascoli ${ }^{1}$, Flávio Ferreira da Silva Binotti ${ }^{2}$, Gabriel Wanderley de Mendonça ${ }^{3}$, Eliana Duarte Cardoso ${ }^{4}$, Edilson Costa ${ }^{2}$

${ }^{1}$ Pós-graduando do Programa de Mestrado em Agronomia da Universidade Estadual do Mato Grosso do Sul, Campus Cassilândia, Mato Grosso do Sul, Brasil (aaascoli@yahoo.com.br)

${ }^{2}$ Prof. Doutor do Programa de Mestrado em Agronomia da Universidade Estadual do Mato Grosso do Sul, Campus Cassilândia, Mato Grosso do Sul, Brasil

${ }^{3}$ Pós-graduando do Programa de Mestrado em Agronomia da Universidade Estadual do Mato Grosso do Sul, Campus Cassilândia, Mato Grosso do Sul, Brasil

${ }^{4}$ Prof. ${ }^{a}$ Doutora do Curso de Agronomia da Universidade Estadual do Mato Grosso do Sul, Campus Cassilândia, Mato Grosso do Sul, Brasil

Recebido em: 03/10/2016 - Aprovado em: 21/11/2016 - Publicado em: 05/12/2016 DOI: 10.18677/EnciBio 2016B 078

\begin{abstract}
A bracatinga (Mimosa scabrella Bentham) é uma árvore nativa das regiões mais frias do Sul do Brasil, podendo ser utilizada na confecção de móveis, na produção de lenha e carvão, na construção civil e na recuperação de áreas degradadas. $O$ objetivo foi avaliar o efeito de diferentes substratos na produção de mudas de bracatinga. Quatro tratamentos foram dispostos em delineamento inteiramente casualizado, com cinco repetições e quatro plântulas por repetição. Cada tratamento foi constituído por substrato (S) composto de diferentes percentuais de esterco bovino $(E)$, terra de barranco $(T B)$ e areia $(A)$, sendo denominados: $\mathrm{S} 1=0 \%$ de $E+$ $70 \%$ de TB $+30 \%$ de $A ; S 2=10 \%$ de $E+60 \%$ de $T B+30 \%$ de $A ; S 3=20 \%$ de $E+$ $50 \%$ de TB $+30 \%$ de $A$; S4 $=30 \%$ de $E+40 \%$ de TB $+30 \%$ de A. Parâmetros analisados: altura de plântulas, diâmetro do colo, comprimento da $p$ arte aérea, comprimento do sistema radicular e fitomassa seca. $\mathrm{O}$ emprego de substrato com $30 \%$ de esterco bovino, $40 \%$ de terra de barranco e $30 \%$ de areia é o mais apropriado para a produção de mudas de bracatinga.
\end{abstract}

PALAVRAS-CHAVE: esterco bovino, Mimosa scabrella Bentham, terra de barranco.

\section{SEEDLING PRODUCTION OF BRACATINGA IN DIFFERENT SUBSTRATES}

\begin{abstract}
The bracatinga (Mimosa scabrella Bentham) is a native tree of the coldest regions of Southern Brazil, It can be used in making furniture, in the production of firewood and charcoal, in civic construction and in rehabilitation of degraded areas. The objective was to evaluate the effect of different substrates in the production of bracatinga seedlings. Four treatments were arranged in a randomized design, with five repetitions and four seedlings by repetition. Each treatment was constituted of substrate (S) composed of different percentage of cattle manure (M), land of steep bank (LSB) and sand (S), being called: $\mathrm{S} 1=0 \%$ de $\mathrm{M}+70 \%$ de $\mathrm{LSB}+30 \%$ de S; S2 $=10 \%$ de $M+60 \%$ de $L S B+30 \%$ de $S ; S 3=20 \%$ de $M+50 \%$ de $L S B+30 \%$ de $S$; ENCICLOPÉDIA BIOSFERA, Centro Científico Conhecer - Goiânia, v. 13 n.24; p. 830 2016
\end{abstract}


S4 $=30 \%$ de $M+40 \%$ de LSB $+30 \%$ de S. Parameters analyzed: the seedling height, the stem diameter, shoot length, length of root system and dry matter. The use of substrate with $30 \%$ of cattle manure, $40 \%$ of land of steep bank and $30 \%$ of sand is the most suitable for the production of seedlings bracatinga.

KEYWORDS: cattle manure, Mimosa scabrella Bentham, land of steep bank.

\section{INTRODUÇÃO}

A bracatinga (Mimosa scabrella Bentham) é uma espécie florestal pertencente à família Fabaceae e a subfamília Mimosoideae. É uma árvore nativa das regiões mais frias do Sul do Brasil, sendo que pode ser encontrada desde o estado do Rio Grande do Sul até o estado de Minas Gerais (ROSA et al., 2012).

A bracatinga pode ser utilizada como matéria-prima na fabricação de chapas de aglomerados, fonte energética e material para construção, também apresentando destaque na confecção de móveis e na produção de lenha e carvão, além da importância como excelente espécie melífera e na recuperação de áreas degradadas (BIANCHETTI, 1981).

A bracatinga é uma espécie perene, sendo muito importante que a formação das mudas possa promover bom desempenho às futuras plantas. Um dos problemas enfrentados na produção de mudas é o crescimento lento apresentado por muitas espécies florestais. Diante disso, torna-se necessário a definição de estratégias que beneficiem a produção com qualidade e em menor tempo, sendo que o uso de substratos adequados proporciona influência na germinação e no crescimento de mudas de espécies florestais (DA ROS et al., 2015).

O crescimento inicial no campo e a produção de madeira estão relacionados com a qualidade da muda produzida no viveiro florestal, onde o substrato é um dos principais fatores que influenciam na busca de melhores características das mudas, sendo desejável o emprego de substratos com adequados atributos físicos e químicos que podem ser obtidos com a utilização de mistura de resíduos orgânicos, conferindo incrementos nas propriedades do substrato (CUNHA-QUEDA et al., 2010).

Deve-se destacar que as principais funções do substrato são a sustentação e a nutrição da planta (DALANHOL et al., 2016). Portanto, a qualidade do substrato a ser utilizado é determinante para que ocorra produção de mudas com elevado padrão, pois contribui para o melhor desenvolvimento das plântulas (YAMANISHI et al., 2004).

O sistema de produção de mudas de espécies florestais tem se mostrado uma atividade fundamental no processo produtivo, para o qual devem ser destinados cuidados na germinação das sementes e no transplante e condução das mudas. Acréscimos significativos de produtividade, resultantes parcialmente do uso de substratos adequados, vêm sendo obtidos nos sistemas de produção de mudas, demonstrando a necessidade de se verificar, para cada espécie vegetal, qual o substrato que permite o melhor desempenho das sementes para a produção de mudas de alta qualidade (MUNIZ et al., 2007). O objetivo foi avaliar o efeito de diferentes substratos na produção de mudas de bracatinga.

\section{MATERIAL E MÉTODOS}

O experimento foi conduzido na Universidade Estadual de Mato Grosso do Sul - UEMS, Unidade Universitária de Cassilândia, localizada a altitude de $516 \mathrm{~m}$, longitude de 5143'15" W e latitude de 1907'21" S (Estação automática 
CASSILANDIA-A742), no município de Cassilândia - MS, no período de 26 de outubro de 2014 a 13 de fevereiro de 2015.

O delineamento utilizado foi o inteiramente casualizado, composto por quatro tratamentos constituídos por cinco repetições com quatro plântulas por repetição. Cada tratamento constituiu-se de substrato composto por diferentes percentuais de esterco bovino, terra de barranco e areia (Tabela 1).

TABELA 1 - Substratos oriundos de mistura de esterco bovino, terra de barranco e areia. UEMS, Cassilândia (MS), 2014

$$
\text { Esterco bovino (E) + Terra de barranco (TB) + Areia (A) }
$$

S1 $=0 \%$ de $\mathrm{E}+70 \%$ de TB $+30 \%$ de $\mathrm{A}$ S $3=20 \%$ de $\mathrm{E}+50 \%$ de $\mathrm{TB}+30 \%$ de $\mathrm{A}$

S2 $=10 \%$ de $E+60 \%$ de TB $+30 \%$ de A S $4=30 \%$ de $E+40 \%$ de TB $+30 \%$ de $A$

O esterco bovino foi compostado em um processo de revolvimento e hidratação em intervalos de dois dias, por um período de 30 dias. Depois desse processo, o esterco foi peneirado e ensacado. Foi realizada a análise química do esterco bovino (Tabela 2).

TABELA 2 - Análise química do esterco bovino utilizado no experimento. UEMS, Cassilândia (MS), 2014

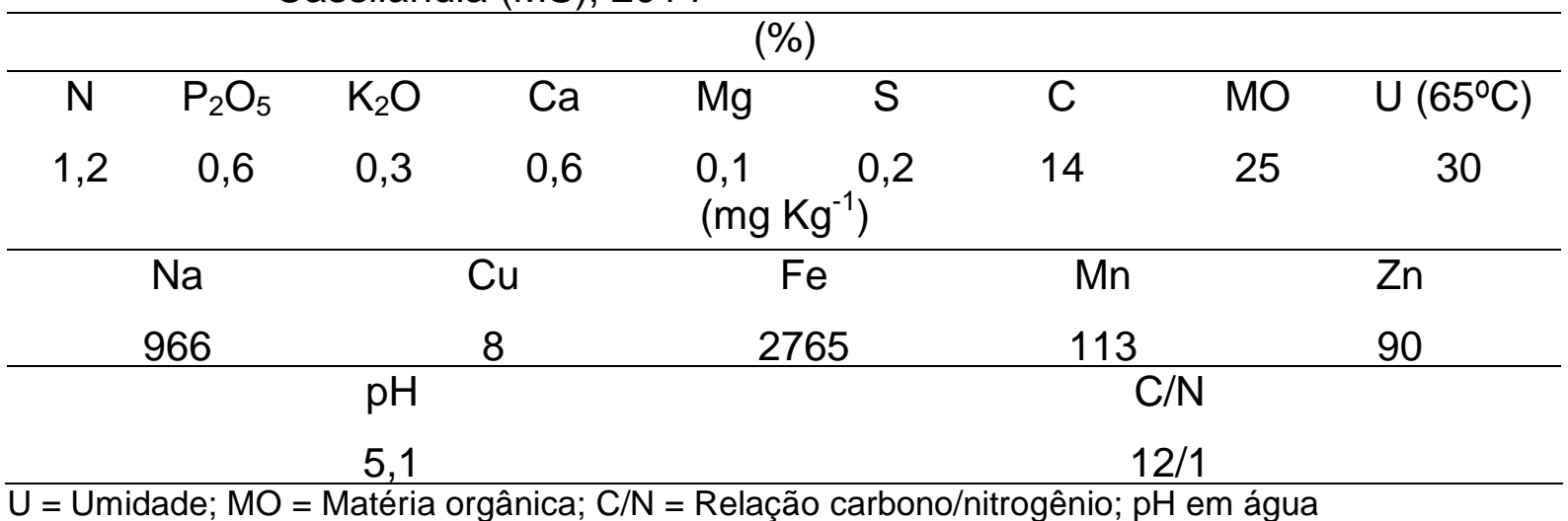

Realizou-se a semeadura das sementes de bracatinga em bandejas alveoladas de plástico preenchidas com areia autoclavada. Em cada bandeja foram semeadas quatro linhas com 50 sementes a uma profundidade de $1 \mathrm{~cm}$. As sementes de bracatinga receberam escarificação mecânica com lixa Norton $n^{\circ} 150$ antes de serem semeadas nas bandejas. Aos vinte dias após a semeadura (20 DAS) foi realizado o transplantio das plantas para sacos de polietileno $(15,0 \times 25,0 \mathrm{~cm})$, com capacidade de 1,8 litros, contendo os substratos descritos anteriormente. $O$ experimento foi conduzido em ambiente protegido caracterizado como telado agrícola de estrutura em aço galvanizado possuindo $8,00 \mathrm{~m}$ de largura por 18,00 m de comprimento e $3,50 \mathrm{~m}$ de altura, fechamento em $45^{\circ}$ graus, com tela preta nas laterais e cobertura, de $50 \%$ de sombreamento. Tanto as bandejas como os sacos plásticos foram irrigados diariamente com a utilização de um regador manual.

\section{Parâmetros analisados:}


Altura de plântulas - Mensurada aos 30 dias após o transplantio. Para dimensionar a altura das plântulas, empregou-se régua graduada em $\mathrm{mm}$, ao longo do caule, sendo avaliada a medida entre o colo e a ramificação mais próxima do ápice da plântula. Os resultados foram expressos em $\mathrm{cm}$.

Diâmetro do colo - Mensurado aos 90 dias após o transplantio. Para obtenção do diâmetro do colo, utilizou-se um paquímetro digital. Os resultados foram expressos em $\mathrm{mm}$.

Comprimento da parte aérea - Aos 90 dias após o transplantio mensurou-se o comprimento da parte aérea das plântulas, com uma régua graduada em $\mathrm{mm}$. $O$ procedimento foi realizado em laboratório e os valores foram expressos em $\mathrm{cm}$ por plântula.

Comprimento do sistema radicular - Aos 90 dias após o transplantio mensurou-se o comprimento da parte radicular das plântulas, com uma régua graduada em $\mathrm{mm}$. Os valores foram expressos em $\mathrm{cm}$ por plântula.

Fitomassa seca de mudas - Aos 90 dias após o transplantio as plântulas foram acondicionadas em estufa e submetidas à secagem por 72 horas a uma temperatura de $65^{\circ} \mathrm{C}$. Posteriormente foi mensurada a fitomassa seca em balança de precisão. Os resultados foram expressos em g por muda.

Quando significativo ao nível de $5 \%$ de probabilidade pelo teste $\mathrm{F}$, aplicou-se o teste de Tukey a $5 \%$ de probabilidade. Para os cálculos estatísticos foi utilizado o programa SANEST (ZONTA \& MACHADO, 1986).

\section{RESULTADOS E DISCUSSÃO}

As mudas de bracatinga dispostas em recipientes contendo substrato $\mathrm{S} 4$ (30\% de $E+40 \%$ de TB $+30 \%$ de A) apresentaram maior altura aos 30 dias após o transplantio que as mudas acondicionadas em recipientes preenchidos com os demais substratos estudados (Tabela 3). Resultados semelhantes aos obtidos por DELARMELINA et al. (2015), na produção de mudas de Chamaecrista desvauxii (Collad.) Killip var. latistipula (Benth.), onde os autores observaram que as plântulas dispostas em substratos com maior percentagem de esterco bovino apresentaram maior altura.

TABELA 3 - Efeito da composição de substratos na altura de plântulas aos 30 dias após o transplantio e na fitomassa seca de mudas aos 90 dias após o transplantio de Mimosa scabrella Bentham. UEMS, Cassilândia (MS), 2015

\begin{tabular}{ccc}
\hline & Altura de plântulas $(\mathrm{cm})$ & Fitomassa seca (g muda) \\
\hline Substratos & & \\
$\mathrm{S} 1$ & $4,80 \mathrm{c}$ & $0,91 \mathrm{~d}$ \\
$\mathrm{~S} 2$ & $4,92 \mathrm{c}$ & $1,61 \mathrm{c}$ \\
$\mathrm{S} 3$ & $7,67 \mathrm{~b}$ & $3,19 \mathrm{~b}$ \\
$\mathrm{~S} 4$ & $8,50 \mathrm{a}$ & $4,34 \mathrm{a}$ \\
\hline C.V.(\%) & 6,00 & 5,84 \\
MMédias seguidas de letras diferentes nas colunas, diferem entre si pelo teste Tukey a 5\% de \\
probabilidade; $\mathrm{S} 1=0 \%$ de $\mathrm{E}+70 \%$ de TB $+30 \%$ de $\mathrm{A} ; \mathrm{S} 2=10 \%$ de $\mathrm{E}+60 \%$ de TB $+30 \%$ de $\mathrm{A} ; \mathrm{S} 3$ \\
$=20 \%$ de $\mathrm{E}+50 \%$ de TB $+30 \%$ de $\mathrm{A} ; \mathrm{S} 4=30 \%$ de $\mathrm{E}+40 \%$ de TB $+30 \%$ de $\mathrm{A}$.
\end{tabular}


A produção de mudas de bracatinga em substrato contendo maior percentual de esterco propiciou as mesmas um maior crescimento evidenciado pela maior fitomassa seca de mudas (Tabela 3), comprimento da parte aérea e diâmetro do colo (Tabela 4) aos 90 dias após o transplantio. Verificou-se que a melhoria no desempenho das mudas de bracatinga para estes parâmetros de crescimento analisados foi proporcional ao aumento no percentual de esterco bovino presente na composição dos substratos em que as plântulas estavam dispostas.

Este comportamento das plântulas diante de crescentes percentuais de esterco bovino presente nos substratos pode ser decorrente do maior aporte de nutrientes a disposição das mudas proveniente de acréscimos de esterco bovino nos substratos, resultando assim em uma maior taxa de crescimento do vegetal. Resultados similares aos obtidos por CRUZ et al. (2016), na produção de mudas de umbuzeiro (Spondias tuberosa Arruda Câmara), onde os autores verificaram que a utilização de esterco bovino na composição dos substratos promoveu maior crescimento do diâmetro do colo das plântulas.

Resultados que também são semelhantes aos obtidos por TRAZZI et al. (2013), na avaliação de substratos orgânicos destinados a produção de mudas de teca (Tectona grandis Linn. F.), onde os autores observaram que plântulas de teca dispostas em substratos compostos por maiores percentuais de esterco bovino apresentaram aumentos no comprimento da parte aérea e na fitomassa seca total. Resultados que também estão em concordância aos obtidos por SILVA et al. (2011), na produção de mudas de mangabeira (Hancornia speciosa Gomes), onde os autores constataram que substratos compostos por percentuais consideráveis de esterco bovino proporcionam acréscimos na fitomassa seca das mudas.

TABELA 4 - Efeito da composição de substratos no comprimento da parte aérea (Comp. da PA), comprimento do sistema radicular (Comp. do SR) e diâmetro do colo de mudas aos 90 dias após o transplantio de Mimosa scabrella Bentham. UEMS, Cassilândia (MS), 2015

\begin{tabular}{cccc}
\hline & Comp. da PA $(\mathrm{cm})$ & Comp. do SR $(\mathrm{cm})$ & Diâmetro do colo $(\mathrm{mm})$ \\
\hline Substratos & & & \\
S1 & $7,97 \mathrm{~d}$ & $31,17 \mathrm{a}$ & $1,11 \mathrm{~d}$ \\
S2 & $9,97 \mathrm{c}$ & $27,22 \mathrm{~b}$ & $1,42 \mathrm{c}$ \\
S3 & $17,40 \mathrm{~b}$ & $22,85 \mathrm{c}$ & $1,81 \mathrm{~b}$ \\
S4 & $22,22 \mathrm{a}$ & $23,30 \mathrm{c}$ & $2,09 \mathrm{a}$ \\
\hline C.V.(\%) & 5,34 & 3,69 & 4,60
\end{tabular}

${ }^{M}$ Médias seguidas de letras diferentes nas colunas, diferem entre si pelo teste Tukey a $5 \%$ de probabilidade; $\mathrm{S} 1=0 \%$ de $\mathrm{E}+70 \%$ de TB $+30 \%$ de $\mathrm{A} ; \mathrm{S} 2=10 \%$ de $\mathrm{E}+60 \%$ de TB $+30 \%$ de $\mathrm{A} ; \mathrm{S} 3$ $=20 \%$ de $\mathrm{E}+50 \%$ de TB $+30 \%$ de $\mathrm{A} ; \mathrm{S} 4=30 \%$ de $\mathrm{E}+40 \%$ de TB $+30 \%$ de $\mathrm{A}$.

As mudas de bracatinga acondicionadas em recipientes contendo substrato S1 $(0 \%$ de $E+70 \%$ de TB $+30 \%$ de $A)$ obtiveram maior comprimento do sistema radicular em relação aos demais tratamentos estudados, aos 90 dias após o transplantio (Tabela 4). Verificou-se que o aumento nos percentuais de esterco bovino em conjunto com a diminuição nos percentuais de terra de barranco nos diferentes substratos estudados pode ter inibido o crescimento do sistema radicular das mudas de bracatinga.

Este padrão em que as mudas tiveram crescimento com menor comprimento do sistema radicular e com maiores teores de fitomassa seca, pode ser decorrente ENCICLOPÉDIA BIOSFERA, Centro Científico Conhecer - Goiânia, v.13 n.24; p. 834 2016 
dos nutrientes estarem em maior disponibilidade em substratos com maior percentual de esterco, possibilitando ao vegetal deixar de investir em um maior crescimento do sistema radicular, uma vez que não é necessário explorar uma quantidade maior do substrato. Evidencia-se que as mudas de bracatinga respondem positivamente ao aumento de esterco bovino no substrato até 0 percentual teste de $30 \%$ de material orgânico.

\section{CONCLUSÃO}

A utilização de substrato composto por $30 \%$ de esterco bovino, $40 \%$ de terra de barranco e $30 \%$ de areia é o mais adequado para a produção de mudas de bracatinga.

\section{REFERÊNCIAS}

BIANCHETTI, A. Comparação de tratamentos para superar a dormência de sementes de bracatinga (Mimosa scabrella Bentham). Boletim de Pesquisa Florestal, $\quad$ n. 2, $\quad$ p. $57 \quad$ - 68. 1981.Disponível em: < http://ainfo.cnptia.embrapa.br/digital/bitstream/CNPF-2009-

09/4872/1/abianchetti2.pdf>.

CRUZ, F. R. S.; ANDRADE, L. A.; FEITOSA, R. C. Produção de mudas de umbuzeiro (Spondias tuberosa Arruda Câmara) em diferentes substratos e tamanho de recipientes. Ciência Florestal, v. 26, n. 1, p. 69 - 80. 2016. Disponível em: <http://dx.doi.org/10.5902/1980509821092>. doi: 10.5902/1980509821092

CUNHA-QUEDA, C.; MORAIS, M. C.; RIBEIRO, H. M.; ALMEIDA, M. H. Caracterização de compostos e de materiais orgânicos para a formulação de substratos para viveiros. Revista de Ciências Agrárias, v. 33, n. 1, p. 367 - 375. 2010. Disponível em: < https://www.repository.utl.pt/bitstream/10400.5/2711/.../REPRCA-367-v33n1a38.pdf $>$.

DALANHOL, S. J.; NOGUEIRA, A. C.; GAIAD, S.; KRATZ, D. Efeito de fungos micorrízicos arbusculares e da adubação no crescimento de mudas de Eugenia uniflora L., produzidas em diferentes substratos. Revista Brasileira de Fruticultura, v. 38, n. 1, p. 117 - 128. 2016. Disponível em: <http://dx.doi.org/10.1590/0100-2945266/14> doi: 10.1590/0100-2945-266/14

DA ROS, C. O.; REX, F. E.; RIBEIRO, I. R.; KAFER, P. S.; RODRIGUES, A. C.; SILVA, R. F.; SOMAVILLA, L. Uso de substrato compostado na produção de mudas de Eucalyptus dunnii e Cordia trichotoma. Floresta e Ambiente, v. 22, n. 4, p. 549 - 558. 2015. Disponível em: <http://dx.doi.org/10.1590/2179-8087.115714>. doi: $10.1590 / 2179-8087.115714$

DELARMELINA, W. M.; CALDEIRA, M. V. W.; FARIA, J. C. T.; LACERDA, L. C. Uso de resíduo orgânico em substrato para produção de Chamaecrista desvauxii (Collad.) Killip var. latistipula (Benth.). Cerne, v. 21, n. 3, p. 429 - 437. 2015. Disponível em: <http://dx.doi.org/10.1590/01047760201521031439>. doi: 10.1590/01047760201521031439 
MUNIZ, M. F. B.; SILVA, L. M.; BLUME. E. Influência da assepsia e do substrato na qualidade de sementes e mudas de espécies florestais. Revista Brasileira de Sementes, v. 29, no 1, p. 140 - 146. 2007. Disponível em: < http://www.scielo.br/pdf/rbs/v29n1/19.pdf>.

ROSA, F. C.; REINIGER, L. R. S.; GOLLE, D. P.; MUNIZ, M. F. B.; CURTI, A. R. Superação da dormência e germinação in vitro de sementes de bracatinga (Mimosa scabrella Bentham). Semina: Ciências Agrárias, v. 33, n. 3, p. 1021-1026. 2012. Disponível em: <http://dx.doi.org/10.5433/1679-0359.2012v33n3p1021>. doi: 10.5433/1679-0359.2012v33n3p1021

SILVA, E. A.; OLIVEIRA, A. C.; MENDONÇA, V.; SOARES, F. M. Substratos na produção de mudas de mangabeira em tubetes. Pesquisa Agropecuária Tropical, v. $41, \quad$ n. 2, p. 279 - 285. 2011. Disponível em:< http://dx.doi.org/10.5216/pat.v41i2.9042>. doi: 10.5216/pat.v41i2.9042

TRAZZI, P. A.; CALDEIRA, M. V. W.; PASSOS, R. R.; GONÇALVES, E. O. Substratos de origem orgânica para produção de mudas de teca (Tectona grandis Linn. F.). Ciência Florestal, v. 23, n. 3, p. 401 - 409. 2013. Disponível em: <http://dx.doi.org/10.5902/1980509810551> doi: 10.5902/1980509810551

YAMANISHI, O. K.; FAGUNDES, G. R.; MACHADO FILHO, J. A.; VALONE, G. V. Efeito de diferentes substratos e duas formas de adubação na produção de mudas de mamoeiro. Revista Brasileira de Fruticultura, v. 26, n. 2, p. 276 - 279. 2004.

Disponível em: < http://www.scielo.br/scielo.php?script=sci_arttext\&pid=S0100$29452004000200023 \& \operatorname{lng}=$ pt\&nrm=iso\&tlng=pt>.

doi: 10.1590/S0100-29452004000200023

ZONTA, E. P.; MACHADO, A. A. Sistema de Análise Estatística para microcomputadores - SANEST. Pelotas-RS: UFPel, Instituto de Física e matemática, $1986.150 \mathrm{p}$. 